\title{
QUEEN'S
UNIVERSITY
BELFAST
}

\section{Everyday pain, analgesic beliefs and analgesic behaviours in europe and russia; An epidemiological survey and analysis}

\author{
Vowles, K. E., Rosser, B., Januszewicz, P., Morlion, B., Evers, S., \& Eccleston, C. (2014). Everyday pain, \\ analgesic beliefs and analgesic behaviours in europe and russia; An epidemiological survey and analysis. \\ European Journal of Hospital Pharmacy, 21(1), 39-44. https://doi.org/10.1136/ejhpharm-2013-000357
}

Published in:

European Journal of Hospital Pharmacy

Document Version:

Peer reviewed version

Queen's University Belfast - Research Portal:

Link to publication record in Queen's University Belfast Research Portal

Publisher rights

Copyright 2014 BMJ. This work is made available online in accordance with the publisher's policies. Please refer to any applicable terms of use of the publisher.

\section{General rights}

Copyright for the publications made accessible via the Queen's University Belfast Research Portal is retained by the author(s) and / or other copyright owners and it is a condition of accessing these publications that users recognise and abide by the legal requirements associated with these rights.

Take down policy

The Research Portal is Queen's institutional repository that provides access to Queen's research output. Every effort has been made to ensure that content in the Research Portal does not infringe any person's rights, or applicable UK laws. If you discover content in the Research Portal that you believe breaches copyright or violates any law, please contact openaccess@qub.ac.uk. 
Please cite as: Vowles, K. E., Rosser, B., Januszewicz, P., Morlion, B., Evers, S., \& Eccleston, C. (2014). Everyday pain, analgesic beliefs, and analgesic behaviours in Europe and Russia: An epidemiological survey and analysis. European Journal of Hospital Pharmacy, 21, 39-44.

Everyday Pain, Analgesic Beliefs, and Analgesic Behaviours in Europe and Russia: An Epidemiological Survey and Analysis

Kevin E. Vowles ${ }^{1}$, Benjamin Rosser ${ }^{2}$, Pawel Januszewicz ${ }^{3}$, Bart Morlion ${ }^{4}$, Stefan Evers ${ }^{5}, \&$ Christopher Eccleston ${ }^{2}$

${ }^{1}$ Department of Psychology, University of New Mexico, Albuquerque, New Mexico, United States of America

${ }^{2}$ Centre for Pain Research, School for Health, University of Bath, Bath, United Kingdom

${ }^{3}$ National Medicines Institute, Warsaw \& Department of Medicine, Rzeszów University, Rzeszów, Poland

${ }^{4}$ The Leuven Centre of Algology \& Pain Management, University Hospitals, Leuven, Belgium

${ }^{5}$ Department of Neurology, University of Münster, Münster, Germany

Correspondence to: Kevin E. Vowles, Ph.D., Department of Psychology, University of New Mexico, Logan Hall MSC03 2220, 1 University of New Mexico, Albuquerque, NM 87131, United States of America, +1 505 277-5676 (tel.), k.e.vowles@gmail.com (e-mail) Keywords: Pain; Europe; Analgesic Use; Analgesic Behaviours; Epidemiology Word count: 3614 


\begin{abstract}
A questionnaire survey was conducted across eight countries, including Belgium, France, Germany, Great Britain, Italy, Poland, Russia, and Spain. Frequency of pain experience was assessed in 8506 individuals (52\% female), as were use of, and attitudes towards, analgesics. Preliminary analyses confirmed the high frequency of pain with $70 \%$ of respondents reporting at least one experience per month. Headache and backache were reported most frequently and the majority, $77 \%$, reported analgesic use in response to pain. Further analyses examined differences across sex, work status, country of residence, and age. In comparison to men, women reported more frequent pain experiences, more analgesic use and worries about use, and tended to base use on what they know about medications. Those who were not unemployed also reported more frequent use and worries about analgesics in comparison to the employed. In general, people living in Russia and Poland reported less frequent pain and analgesic use in comparison with the rest of Europe. They also reported more worries about analgesics and that their analgesic use had little to do with analgesic knowledge. Regarding age, younger individuals reported fewer pain episodes, more frequent analgesic use, and less worry about analgesics in comparison with older individuals. In addition, younger individuals were more likely to base analgesic use on what they knew about the medicine. These findings replicate extant findings with regard to the frequency of pain. They also provide new information on differences in pain experience, analgesic use, and attitudes towards analgesics across Europe and Russia.
\end{abstract}




\section{INTRODUCTION}

Many disease states include pain as a prominent symptom, and pain is the commonest reason for healthcare visits ${ }^{1,2}$. Epidemiological surveys have determined prevalence rates of chronic and acute pain in the general population, with largely consistent results. Prevalence estimates of current acute or chronic pain range from $25 \%$ to $49 \%$ and from $19 \%$ to $22 \%$ for chronic pain alone $e^{5,6}$. These surveys have described features of pain presentation including the increased representation of women in pain report ${ }^{5,6}$, the association of pain with disability such as work absenteeism ${ }^{7}$, and site of pain, with head and low back pain dominating (e.g., ${ }^{8}$ ), especially in older adults ${ }^{9,10}$.

Although demographic description is useful, the frequency of analgesic use and the psychological factors that influence consumption practices are particularly interesting but relatively under-investigated. There have been a handful of surveys performed, such as Hamunen et al.'s ${ }^{11}$ review of opioid use in Europe; however, there is little information on analgesic use generally in the community. Furthermore, there is no population-based information of how knowledge and attitudes about analgesics, including worries, influence analgesic use.

The purpose of this survey was to evaluate the frequency of pain experiences in the general population across seven European countries and Russia, and to assess patterns of use and attitudes towards analgesic medications. In order to capture the broadest array of findings, we focused on the experience of common or "everyday" pain and made no distinction between chronic and acute pain, nor with regard to pain intensity or quality.

\section{METHODS}

The survey material was developed by a group of experts from several pain-related fields including general practice, specialist pain clinics, sports science, neurology, and pharmacology, 
from across the eight countries surveyed. The survey was translated into local languages by freelance translators or local fieldwork agencies. It was then back translated to ensure internal consistency.

\section{Participants}

Data collection was performed by a professional service offering access to a large and diverse panel of adults who had previously consented to take part in survey research. In the majority of countries surveyed (i.e., Belgium, France, Germany, Great Britain, Italy, and Spain), a questionnaire survey was e-mailed to a random selection of individuals from these panels. In Poland and Russia, computer assisted personal interviews were carried out at respondent's home, as it was presumed that individuals in these countries would have lower levels of internet $\operatorname{access}^{12}$. For these latter two countries, interviewers read the questionnaire aloud, showed respondents a screen with response choices, and then coded respondent answers.

Overall, $57 \%$ of those approached declined participation and $8 \%$ who began the survey dropped out before completing it in full. No information is available on those who declined participation or dropped out early. A donation to a charity of the respondent's choice was made upon completion of the survey.

In total, 8506 respondents (51.5\% female) completed the survey, with at least 1000 individuals from each country (range 1004 for Poland to 1121 for Italy). Respondent age at the time of the survey was recorded and coded into cohort groups of 16-24 $(\mathrm{n}=1407), 25-34(\mathrm{n}=$ 1872), 35-44 $(\mathrm{n}=1965), 45-54(\mathrm{n}=1762), 55-64(\mathrm{n}=1081)$, and 65+ $(\mathrm{n}=419)$. Work status

was also recorded with $62.0 \%$ of respondents reporting that they were employed (e.g., paid work, enrolled in education, housewife/husband). 


\section{Measures}

The survey was divided into three primary domains of interest: (1) pain experiences, (3) analgesic consumption, and (3) beliefs and attitudes regarding analgesics. A description of each of these areas is provided in the following sections.

\section{Pain Experiences}

All respondents were asked about experiences with seven common pain types: mild/ moderate headache, severe/migraine headache, "hangover", sports injury/muscle pain, backache, illness (i.e., cold/flu/sore throat), and toothache. In addition women $(n=4381)$ were asked whether they experienced period pain. Pain types were selected via consensus from an international panel of experts. Pain frequency was evaluated on a five-point categorical scale; response categories were "never", "once a year or less", "once every three months", "one to two times a month", and "three times a month or more". These responses were coded $0,1,2,3$, or 4, respectively.

\section{Analgesic Consumption Frequency and Dosing}

For each pain type experienced, respondents were asked to rate frequency and dosage of analgesic use (including over-the-counter and prescribed) relative to instructions included with the medicine. Both frequency and dosage were rated on a three point categorical scale. Response categories for frequency of use included "take less often than stated on packet", "take exactly as often as stated on the packet", and "take more often than stated on packet". Response categories for dosage included "take at a lower dose than stated on packet", "take at exactly the dose stated on packet", and "take at a higher dose than stated on packet". These responses were coded as 0 , 1 , or 2 , respectively. 
The original intent of the analyses was to examine the analgesic frequency and dosing variables separately in the main analyses, however, the measures were found to be highly correlated $(r=0.89, \mathrm{p}<.001)$ and the pattern of results was identical, therefore, they were summed to form a single measure, which we simply term as Analgesic Use in the remainder of this report. Further, all analyses involving the Analgesic Use variable used data from participants who reported at least one pain experience per month $(n=5552)$. Raw scores were converted to zscores.

\section{Beliefs and Attitudes regarding Analgesics}

The final sections of the questionnaire provided respondents with a series of statements about analgesic medication and asked them to agree or disagree with these statements. These statements are displayed in Table 1.

In order to reduce the number of variables for analysis, higher-order factor analytic methods were used to distill factors from participant responses. These higher-order methods increase the reliability of factor structure when dichotomous data are involved and entail the completion of two factor analyses, an initial one consisting of the dichotomous responses to establish lower-order factors, and a second consisting of the lower-order factors to establish higher-order, overarching factors ${ }^{13}$.

The initial factor analysis of the dichotomous items (see Table 1) used maximum likelihood method of extraction with promax rotation to allow for inter-correlation amongst factors. Initially, four items had factor loadings below established cut-offs (i.e., $0.32{ }^{14}$ ); these items were excluded from further analysis. The subsequent factor analysis indicated a seven factor structure was appropriate based on review of factor loadings, eigenvalues (all > 1.0), and variance estimates. Total variance accounted for by the factors was $48 \%$. Factor loadings were 
parsimonious and interpretable with no indication of significant crossloading. Factors were labeled: Worry about Analgesics, Beliefs that Analgesics are Safe and Effective, Analgesic Qualities: Onset and Duration, Take Analgesic as Soon as Pain Occurs, Knowledge About How Analgesics Work, Safety Advice from Health Experts, and Dosing Practices: Titration. The right side of Table 1 displays loadings and factor labels.

A higher order factor analysis using these seven factor scores was performed, which indicated the presence of two overarching factors. All factor loadings were acceptable. Further, Eigenvalues were 3.41 and 1.56 and the factors accounted for $49 \%$ and $22 \%$ of the variance, respectively. The first higher order factor was labeled 'Knowledge and Beliefs Related to Analgesic Use' and consisted of five of the lower order factors (Beliefs that Analgesics are Safe and Effective, Analgesic Qualities: Onset and Duration; Knowledge About How Analgesics Work, Safety Advice from Health Experts, Dosing Practices: Titration). The second higher order factor was labeled 'Worries about Analgesic Use' and consisted of the remaining lower order factors [Worry about Analgesics, Take Analgesic as Soon as Pain Occurs (negative loading)].

\section{RESULTS}

\section{Number of Pain Experiences per Month}

Descriptively, the majority $(70 \% ; \mathrm{n}=5983)$ of respondents reported at least one episode of pain per month. Most of these individuals experienced between one and three episodes per month ( $\mathrm{n}=4999 ; 59 \%$ of total sample), while only a small number reported four or more episodes $(n=984 ; 12 \%$ of total sample). Mean number of pain episodes was $1.58(\mathrm{SD}=1.46$; median $=1.0 ;$ Range: $0-8$ ). The most frequently pains were mild/moderate headache and backache, which were reported by $43 \%$ and $40 \%$ of the sample, respectively. Figure 1 displays percent frequency of pain types among respondents. 
Our main focus was to determine whether differences were present in pain experiences per month across sex, employment status, country of residence, or age group. For all analyses, primary interpretation was based on main effects. While interactions amongst variables were observed, the overall pattern was exceptionally complex and no overarching patterns were discerned. All interactions are detailed in the Appendix.

\section{Sex Differences}

With regard to sex differences, the total number of pain experiences per month were tallied after excluding period pain as this occurred only in women. Results indicated a significant difference, $F(1,8506)=571.6, p<.001$, between the sexes with women $(M=1.6 ; S D=1.3)$ reporting significantly more pain experiences per month then men $(M=1.2 ; S D=1.3)$.

\section{Employment Status Differences}

Regarding work status, those who were unemployed reported more frequent monthly pain experiences, $F(1,8506)=571.6, p<.001$. Those who were employed reported an average of 1.5 episodes per month $(\mathrm{SD}=1.4)$, while the unemployed reported an average of 1.7 episodes per month $(\mathrm{SD}=1.5)$.

\section{Country of Residence Differences}

Differences across countries were also indicated, $F(7,8506)=10.2, p<.001$. Individuals residing in Poland reported fewer pain episodes per month $(M=1.2 ; S D=1.3)$ than all other counties (Grand $\mathrm{M}=1.6 ; S D=1.5)$. No other differences were indicated between countries.

\section{Age Group Differences}

Finally, a complex pattern of differences was indicated across age groups, $F(5,8506)=$ 42.5, $p<.001$. The general pattern, displayed in Figure 2, was one of more frequent pain experiences during the younger years (16-24, 25-34), which gradually decreased in frequency 
during the middle ages $(35-44,45-54,55-64)$, and then increased in the eldest group (65+).

Statistically, the youngest age group, 16-24, reported significantly more frequent pain per month in comparison to all other groups, while the 25-34, 35-44, and 65+ year olds reported significantly more frequent pain per month in comparison to 45-54 and 55-64 year olds. No other pairwise comparisons were significant.

\section{Analgesic Use, Knowledge and Beliefs, and Worries}

Overall, analgesic use was common with an average of $77 \%$ of individuals reporting analgesic use across the pain types (Range: $61 \%$ for Backache to $93 \%$ for Severe/Migraine Headache; Median: 76\%). Consistent with the pain frequency analyses, the primary purpose of these analyses was to determine differences in analgesic use, knowledge and beliefs, and worries across sex, employment status, country of residence and age group. No interaction effects were indicated across these variables, therefore, analyses consisted solely of interpretation of main effects. Table 2 provides descriptive and statistical information for all analgesic variables.

\section{Sex Differences}

Women reported significantly greater analgesic use then men, $F(1,5551)=29.7, p<$ .001 , as well as greater worries about analgesic use, $F(1,8505)=58.0, p<.001$. They reported basing their analgesic use more on knowledge and beliefs about analgesics in comparison to men, $F(1,8505)=13.4, p<.001$.

\section{Employment Status Differences}

Those who were employed reported less analgesic use in comparison to those who were employed, $F(1,5551)=16.9, p<.001$, as well as lesser worries about use, $F(1,8505)=10.5, p$ $<.001$. There were no significant differences between the two groups with regard to the influence of knowledge and beliefs on use, $F(1,8505)=0.7, p<.39$. 


\section{Country of Residence Differences}

With regard to country of residence, there were significant differences indicated for all three analgesic variables, all $F$ 's $>22.6$, all $p$ 's $<.001$. For Analgesic Use, respondents living in Great Britain reported more frequent use of analgesics in comparison to all other countries, while individuals living in Belgium and Poland reported less use in comparison to all other counties. Individuals living in France reported more analgesic use in comparison to those living in Italy. No other pairwise comparisons were significant.

A complex pattern of differences emerged with regard to the influence of Analgesic Knowledge and Beliefs on use. Specifically, individuals living in Italy, Poland, and Russia reported basing analgesic use less on knowledge and beliefs about medication in comparison to France, Germany, Great Britain, and Spain. Individuals living in Belgium tended to fall in the middle of these two groups, with significantly higher scores on this measure in comparison to individuals living in Poland and Russia and significantly smaller scores than those living in Germany and Spain. All other comparisons were non-significant.

Finally, regarding Worries About Analgesic Use, respondents living in Russia reported significantly greater worries about analgesics in comparison to all other countries assessed, while individuals living in Belgium and Germany reported less worry in comparison to all other countries assessed, with the former reported significantly less worry than the latter. Those living in Poland reported more worries in comparison to those living in Belgium, France, Germany, and Italy. No other differences were significant.

\section{Age Group Differences}

For all three variables involving analgesics, significant differences across the age groups were indicated, all $F^{\prime}$ s $>10.6$, all $p$ 's $<.001$. In the evaluation of analgesic use, individuals in the 
25-34 and 35-44 year old age ranges reported greater use of analgesics in relation to individuals in all other age ranges. There was also a difference between individuals aged $65+$ and those aged 45-54, with latter group reporting greater use. No other pairwise differences were indicated.

With regard to the effect of Analgesic Knowledge and Beliefs on Use, the general trend was for individuals in the eldest age groups to report basing analgesic consumption less on knowledge and beliefs about medications. Specifically, individuals in the eldest two age groups (i.e., 55-64, 65+) reported basing analgesic consumption less on knowledge and beliefs about medication in comparison to individuals from the four younger age groups. In addition, individuals in the $65+$ age group had significantly lower scores on this measure in comparison to those in the 55-64 age group. The only other significant difference occurred between the 25-34 and 35-44 age groups, with the latter having significantly higher scores on this measure.

Finally, with regard to Worries about Analgesics, in general the youngest age group reported the least amount of worry, the eldest group the most, and there were few differences observed among the middle aged groups. In detail, individuals aged 16-24 reported less worry about analgesics in comparison to all other age groups, with the sole exception of those aged 5564 where there were no significant differences. Individuals aged 65 or older reported significantly more worry in comparison to all other age groups, with the sole exception of individuals aged 35-44. The only other significant difference occurred between individuals in the 35-44 and 55-64 age groups, with the latter reporting significantly greater worry than the former.

\section{DISCUSSION}

The results of this study indicate that the experience of pain in Europe and Russia is extremely common, with $70 \%$ of this international sample reporting at least one pain experience per month. The average individual experienced between one and two episodes and only a 
minority $(12 \%)$ reported four or more experiences per month. The most frequently occurring pain experiences were mild/moderate headache (43\%) and backache (40\%); the least frequent was toothache $(5 \%)$. Furthermore, the vast majority of individuals $(\sim 80 \%)$ reported taking analgesic medication in response to the pain experienced.

Poland and Russia reported less pain in comparison to the rest of Europe, used fewer analgesics, based use less on analgesic knowledge and beliefs, and were more worried about analgesic use. It is unfortunate that the method of data collection was different for these two countries in comparison to the others as it presents an alternative explanation for the pattern of findings. These concerns are somewhat attenuated by studies indicating that method of data collection (i.e., computerized, face-to-face, paper, telephone) does not affect reporting of physical status and pain experience ${ }^{15,16}$; nonetheless, they cannot be entirely discounted.

Across the whole of Europe, younger people tended to have fewer pain experiences in comparison to those who are older. Again, this finding is consistent with those of previous studies $^{8,9}$. It is noteworthy, however, that despite this difference in pain experience, younger individuals reported more frequent analgesic use in response to pain than older individuals. Additionally, younger individuals report that they based use on what they know about the medications. Younger people were also less worried about analgesics in comparison to older people, although their criteria for analgesic selection may differ (e.g., ${ }^{17}$ ). Further, one recent study concerned with medication adherence in chronic pain sufferers indicated that younger age was possibly a determinant of poor adherence to prescription regimens and was linked with both over- and underuse of medications ${ }^{18}$. There may be a number of explanations for this finding, all of which are hypothetical at this point. For example, it may be that younger individuals are more familiar with medications as they have been raised in a society where analgesics are generally 
regarded as safe and efficacious - in addition, these medications are often readily available. Alternatively, the differences amongst the age group may be a product of longitudinal experiences over the lifespan.

Differences were also observed among the sexes and based on employment status, which essentially replicates findings reported in previous work ${ }^{5-7}$. In brief, women reported more frequent pain and greater frequency of, and worries about, analgesic use in comparison to men. A similar pattern was observed with regard to differences among the employed and unemployed, with the latter reporting more frequent pain, analgesic use and worries.

It is important to note that no objective measure of adherence to instructions for analgesic use was included in the present study. Therefore, we are only able to comment on differences in patterns of use among the dependent variables used and not on whether these differences constitute over- or under-use of these medicines.

There are other limitations to note as well. First, while cross-sectional survey data are useful in providing general information across a wide slice of a population, they do not allow for causal conclusions or for a detailed analysis at the level of individual pain experiences or behaviours in response to pain. For example, we did not distinguish between different analgesic behaviours or medications, nor did we record pain intensity or quality. Further, no information was available for those who declined participation or who did not complete the questionnaire survey. These issues limit our ability to speak to the generalizability of these results. Second, all data were self-report and there is no way to determine how inaccuracies in recall, response biases, or perceived social pressures influenced the data collected. Third, as noted, the difference in data collection methods between Poland, Russia and the other countries, although necessary, influences our confidence in the observations comparing across Eastern and Western Europe. 
Finally, the fact that the majority of data was collected via computer means that that older individuals were potentially undersampled, as they may be less likely to have access to or be proficient enough in their use of this technology to have taken part in the survey.

This research can lay the groundwork for future analgesic planning in the major European economies. In particular, European states traditionally have had very different attitudes to accessing analgesic drugs, and have had different exposure to information about analgesics and optimum pain management. By discovering how individuals experience and respond to pain, as well as how they make decisions on what they should do about it, we can better understand the experience of pain, which should allow improvements in everyday pain management across Europe. 
Table 1

Factor Loadings for Analgesic Medication Statements.

\begin{tabular}{|c|c|}
\hline Item & Lower-order Factor Label (Factor Loading) \\
\hline \multicolumn{2}{|c|}{$\underline{\text { Attitudes Towards Analgesics }}$} \\
\hline I would rather take a painkiller than suffer with pain. & Analgesic Qualities: Onset and Duration (.47) \\
\hline Painkillers are a safe means of relieving general aches and pains. & Safety Advice from Health Experts (.35) \\
\hline I believe non-medicinal methods of pain relief are preferable. & Worry about Analgesics (.45) \\
\hline I think most painkillers are too strong to take for everyday aches and pains. & Worry about Analgesics (.34) \\
\hline I believe I can take different types of painkillers together. & Knowledge About How Analgesics Work (.35) \\
\hline If I take one type of painkiller too many times I will become resistant to it. & Excluded-did not load. \\
\hline I am worried about side effects when I take a painkiller. & Worry about Analgesics (.43) \\
\hline $\begin{array}{l}\text { I would like to be able to access painkillers in the supermarket, newsagent, or } \\
\text { grocers. }\end{array}$ & Excluded-did not load. \\
\hline
\end{tabular}

\section{Analgesic Use}

I take a painkiller as soon as pain occurs.

Take Analgesic as Soon as Pain Occurs (.99)

I take the painkiller I think will remove my pain as quickly as possible.

Analgesic Qualities: Onset and Duration (.48)

I take a small dose initially, then increase this if the pain does not diminish.

Dosing Practices: Titration (.47)

I wait for a short period of time before taking a painkiller and then, if pain

Safety Advice from Health Experts (.41)

persists, will take one.

I take a weaker painkiller to start with and will only 'upgrade' to a stronger

Dosing Practices: Titration (.56)

painkiller if pain persists.

(Table continues) 
Table 1 (con't)

I only take painkillers for particularly severe pain (when the pain is preventing

Worry about Analgesics (.39) me from carrying out normal tasks).

I take painkillers preventatively (before pain occurs).

Excluded-did not load.

I take different painkillers for different types of pain.

Knowledge About How Analgesics Work (.61)

Factors Influencing Choice of Analgesics

How quickly pain is removed.

How long pain relief lasts.

The painkiller is stronger than others.

The painkiller is safe to take (has no side effects).

The painkiller is suitable for all types of pain.

The painkiller targets a specific type of pain (e.g., period pain).

The painkiller is value for money.

The painkiller is easy to take (e.g., easy to swallow).

Recommendation from friends or family.

Recommendation from healthcare professional.

The painkiller is a brand I can trust.

Painkiller choice not based on any of the options listed.
Analgesic Qualities: Onset and Duration (.72)

Analgesic Qualities: Onset and Duration (.48)

Knowledge About How Analgesics Work (.32)

Safety Advice from Health Experts (.38)

Belief that Analgesics are Safe and Effective

Knowledge About How Analgesics Work (.38)

Belief that Analgesics are Safe and Effective

Belief that Analgesics are Safe and Effective

Excluded-did not load

Safety Advice from Health Experts (.40)

Belief that Analgesics are Safe and Effective

Safety Advice from Health Experts (-.55) 
Table 2

Z-Score Means (SD's) for Analgesic Variables

\begin{tabular}{|c|c|c|c|}
\hline Variable & Analgesic Use & $\begin{array}{l}\text { Knowledge and Beliefs } \\
\text { Related to Analgesic Use }\end{array}$ & $\begin{array}{l}\text { Worries About } \\
\text { Analgesic Use }\end{array}$ \\
\hline \multicolumn{4}{|l|}{$\underline{\text { Sex }}$} \\
\hline Men & $-0.09(1.00)^{\mathrm{a}}$ & $-0.10(0.98)^{\mathrm{a}}$ & $-0.10(0.84)^{\mathrm{a}}$ \\
\hline Women & $0.06(1.00)^{\mathrm{b}}$ & $0.10(0.94)^{\mathrm{b}}$ & $0.11(0.88)^{\mathrm{b}}$ \\
\hline \multicolumn{4}{|l|}{ Employment Status } \\
\hline Employed & $-0.04(1.0)^{\mathrm{a}}$ & $-0.01(0.9)^{\mathrm{a}}$ & $-0.02(0.83)^{\mathrm{a}}$ \\
\hline Unemployed & $0.07(1.0)^{b}$ & $0.01(1.0)^{\mathrm{a}}$ & $0.04(0.84)^{b}$ \\
\hline \multicolumn{4}{|l|}{ Country } \\
\hline Belgium & $-0.22(0.93)^{\mathrm{a}}$ & $0.11(0.95)^{\mathrm{a}, \mathrm{d}}$ & $-0.18(0.78)^{\mathrm{a}}$ \\
\hline France & $0.10(0.99)^{b}$ & $0.22(0.95)^{\mathrm{b}, \mathrm{d}}$ & $0.02(0.81)^{b}$ \\
\hline Germany & $-0.02(1.04)^{\mathrm{b}, \mathrm{c}}$ & $0.24(1.00)^{\mathrm{b}}$ & $-0.33(0.80)^{\mathrm{c}}$ \\
\hline Great Britain & $0.28(1.10)^{\mathrm{d}}$ & $0.19(0.95)^{\mathrm{b}, \mathrm{d}}$ & $-0.04(0.82)^{\mathrm{b}, \mathrm{d}}$ \\
\hline Italy & $-0.08(0.95)^{\mathrm{c}}$ & $0.001(0.90)^{\mathrm{c}, \mathrm{d}}$ & $-0.04(0.84)^{\mathrm{b}}$ \\
\hline Poland & $-0.28(0.90)^{\mathrm{a}}$ & $-0.56(0.83)^{\mathrm{c}}$ & $0.14(0.84)^{\mathrm{d}}$ \\
\hline Russia & $0.07(0.99)^{\mathrm{b}, \mathrm{c}}$ & $-0.43(0.73)^{\mathrm{c}}$ & $0.27(0.93)^{\mathrm{e}}$ \\
\hline Spain & $0.08(0.98)^{\mathrm{b}, \mathrm{c}}$ & $0.24(0.93)^{b}$ & $0.12(0.92)^{\mathrm{b}, \mathrm{d}}$ \\
\hline \multicolumn{4}{|l|}{ Age Group } \\
\hline $16-24$ & $-0.10(1.00)^{\mathrm{a}, \mathrm{c}}$ & $0.05(1.00)^{\mathrm{a}, \mathrm{b}}$ & $-0.09(0.84)^{\mathrm{a}, \mathrm{b}}$ \\
\hline $25-34$ & $0.04(1.04)^{\mathrm{b}}$ & $0.01(0.97)^{\mathrm{a}}$ & $0.001(0.86)^{\mathrm{c}}$ \\
\hline $35-44$ & $0.13(1.02)^{b}$ & $0.10(0.96)^{b}$ & $0.04(0.87)^{\mathrm{c}, \mathrm{d}}$ \\
\hline $45-54$ & $0.01(0.99)^{\mathrm{c}}$ & $0.06(0.94)^{\mathrm{a}, \mathrm{b}}$ & $0.01(0.86)^{\mathrm{c}}$ \\
\hline $55-64$ & $-0.11(0.91)^{\mathrm{a}, \mathrm{c}}$ & $-0.15(0.94)^{\mathrm{c}}$ & $0.17(0.87)^{\mathrm{b}}$ \\
\hline $65+$ & $-0.20(0.87)^{\mathrm{a}}$ & $-0.54(0.79)^{\mathrm{d}}$ & $0.17(0.87)^{\mathrm{d}}$ \\
\hline
\end{tabular}

Note: Different superscripts indicate statistically significant between group differences at a Bonferronicontrolled alpha. 


\section{FIGURE CAPTIONS}

Figure 1: Frequency of pain experiences across the sample $(N=8506 ; n=4381$ for period pain in women)

Figure 2: Mean pain experiences per month across the age groups. Different superscripts indicating statistically significant differences at a Bonferroni-controlled alpha. 


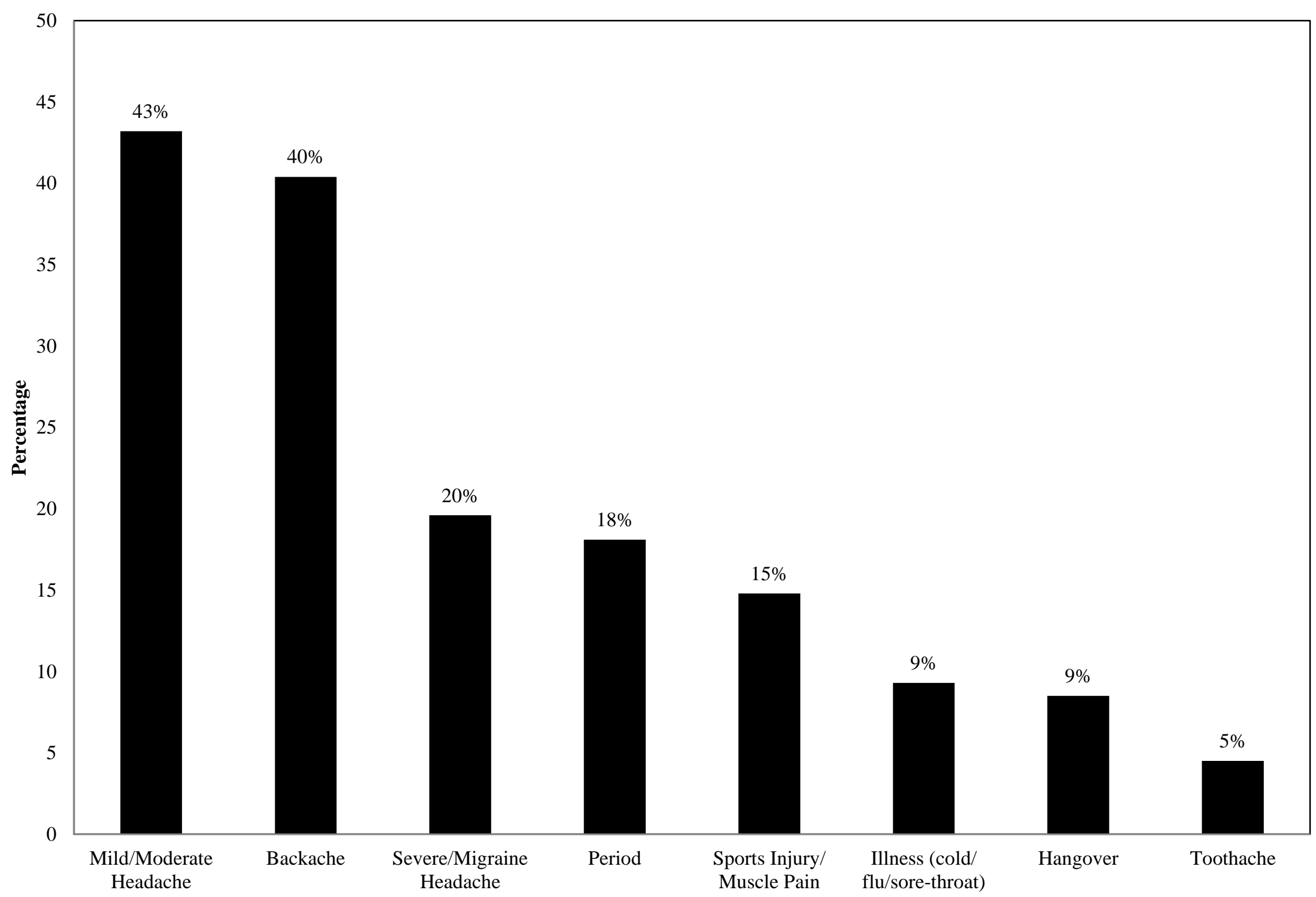




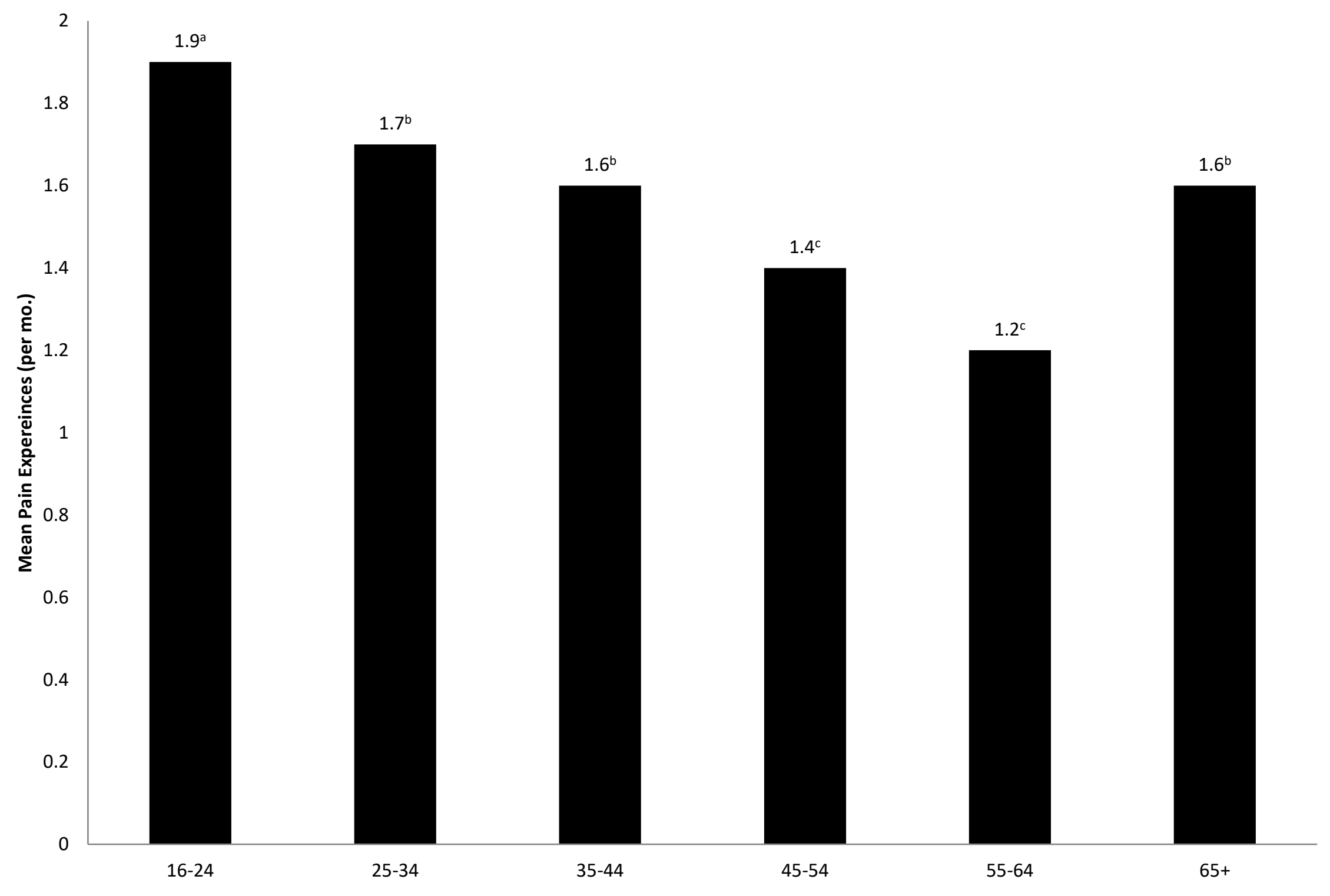




\section{NOTES}

Competing Interest: The authors have no competing interests to declare.

Funding: This research was partly funded by an unrestricted educational grant from Reckitt Benkiser.

Contributorship: This research arose from ideas discussed by a European Pain Forum consisting of: Dr Anita Biswas, Professor Christopher Eccleston, Professor Stefan Evers, Professor Pawel Januszewicz, Dr Dipak Kanabar, Dr Rosemary Leonard, Dr Bart Morlion, Professor Sharov Mikhail Nicolaevich, Dr Denis Pouchain, Dr Ricardo Ruiz-López, Professor Francesco Scaglione, and Professor Alain Serrie. Additionally, the authors wish to thank Professor Witold Gumulka, Dr. Agata Maciejczyk, and Dr. Eva Cyhlarova for their feedback and comments on previous versions of this manuscript.

License: The Corresponding Author has the right to grant on behalf of all authors, and does grant on behalf of all authors, an exclusive license (or non-exclusive for government employees) on a worldwide basis to the BMJ Group and co-owners or contracting owning societies (where published by the BMJ Group on their behalf), and its Licensees to permit this article (if accepted) to be published in the European Journal of Hospital Pharmacy and any other BMJ Group products and to exploit all subsidiary rights, as set out in our license. 
Appendix

\section{Overview of Interactions}

There were significant 2-way interactions for all three combinations of sex, age group, and nationality, all F's $<1.8$, all p's $<0.05$. There was no evidence of a significant 3-way interaction, all F's $<1.44$, all p's $>0.17$, nor was there evidence of any interactions with work status, all $F$ 's $<1.5$, all $p$ 's $>0.23$. Specific findings of pairwise comparisons are detailed below. More details of these interactions are available from the authors upon request.

\section{Interactions of Country of Residence and Sex}

Women in Poland reported fewer episodes of pain per month $(M=1.48, S D=1.36)$ than women living in the seven other countries assessed (Belgium: $M=1.98, S D=1.47$; France: $M=$ 1.93, $S D=1.51$; Germany: $M=1.91, S D=1.46$; Great Britain: $M=2.00, S D=1.51$; Italy $M=$ 2.10, $S D=1.53$; Russia: $M=1.90, S D=1.46$; Spain: $M=2.25, S D=1.55)$. Women in Spain reported a greater number of episodes in comparison to five of the other seven counties, including Belgium, France, Germany, Poland, Russia, but not Great Britain or Italy. Finally, women in Russia reported fewer pain episodes in comparison to women in Italy. No other differences were significant.

With regard to men, men in Poland reported fewer episodes of pain per month than men living in six of the seven other countries assessed (Belgium: $M=1.16, S D=1.29$; France: $M=$ 1.27, $S D=1.39$; Great Britain: $M=1.38, S D=1.40$; Italy $M=1.20, S D=1.41$; Spain: $M=1.31$, $S D=1.31$; Russia: $M=1.31, S D=1.36)$. The only exception was for Germany (Germany: $M=$ $1.10, S D=1.20$ ), where there were no significant differences present. No other differences were significant. 
Overall, there was not a consistent pattern of results with regard to the age and country of residence. Generally, individuals living in Poland at the youngest three age ranges reported fewer pain experiences per month than most of the other countries assessed, with the sole exception of Russia, where there were no differences indicated. Generally, individuals living in Russia tended to report fewer pain experiences at the two younger age groups in comparison to other countries, while conversely, for the eldest age group analyzed (45 - 54 years old) a greater number of pain experiences were reported. No differences were reported across the $35-44$ age group. 


\section{REFERENCES}

1. Kerns RD, Otis J, Rosenberg R, et al. Veterans' reports of pain and associations with ratings of health, health-risk behaviors, affective distress, and use of the healthcare system. J Rehabilitation Research and Development 2003;40:371-379.

2. Koleva D, Krulichova I, Bertolinin G, et al. Pain in primary care: An Italian survey. Eur J Public Health 2005;15:475-479.

3. Portenoy RK, Ugarte C, Fuller I, et al. Population-based survey of pain in the United States: Differences among White, African American, and Hispanic subjects. J Pain 2004;5:317-328.

4. Schmidt CO, Raspe H, Pfingsten M, et al. Backpain in the German adult population prevalence, severity, and sociodemographic correlates in a multiregional survey. Spine 2007;32:2005-2011.

5. Breivik H, Collett B, Ventafridda V, et al. Survey of chronic pain in Europe: Prevalence, impact on daily life, and treatment. Eur J Pain 2006;10:287-333.

6. Gureje O, Von Korff M, Simon GE, et al. Persistent pain and well-being: A World Health Organization study in primary care. JAMA 1998;280:147-151.

7. Gerdle B, Björk J, Henriksson C, et al. Prevalence of current and chronic pain and their influences upon work and healthcare-seeking: A population study. J Rheumatol 2004;31: 1399-1406.

8. Watkins EA, Wollan PC, Melton J, et al. A population in pain: Report from the Olmsted Country Health Study. Pain Med 2008;9:166-174.

9. Cassidy JD, Côté P, Carroll LJ, et al. Incidence and course of low back pain episodes in the general population. Spine 2005;30:2817-2823. 
10. Parsons S, Breen A, Foster NE, et al. Prevalence and comparative troublesomeness by age of musculoskeletal pain in different body locations. Fam Pract 2007;24:308-316.

11. Hamunen K, Laitinen-Parkkonon P, Paakkari P, et al. What do different databases tell about the use of opioids in seven European countries in 2002? Eur J Pain 2008;12:705-715.

12. Wallstein S. Regulation and internet use in developing countries. Econ Dev Cultural Change 2005;53:501-523.

13. Baldwin KA, Grinslade MS, Baer LC, et al. Higher-order factor analysis of an instrument with dichotomous data. Res Nursing Health 2005;28:431-440.

14. Tabachnick BG \& Fidell LS. Using multivariate statistics (4th ed.). Harper-Collins: New York, 2001.

15. Cook AJ, Roberts DA, Henderson MD, et al. Electronic pain questionnaires: A randomized, crossover comparison with paper questionnaires for chronic pain assessment. Pain 2004;110:310-317.

16. Lungenhausen M, Lange S, Maier C, et al. Randomised controlled comparison of the Health Survey Short Form (SF-12) and the Graded Chronic Pain Scale (GCPS) in telephone interviews versus self-administered questionnaires. Are the results equivalent? BMC Med Res Methodol 2007;7:50.

17. Nowakowska-Zajdel E, Kokot $\mathrm{T}$, et al. Taking nonsteroidal anti-inflammatory drugs by teenagers from Zawiercie. Ann Acad Med Siles 2007; 61: 372-375.

18. Broekmans S, Dobbels F, Milisen K, et al. Medication adherence in patients with chronic non-malignant pain: Is there a problem? Eur J Pain 2009;13:115-123. 